\title{
Cell-mediated immunity to gluten fraction III in adult coeliac disease
}

\author{
A. W. BULLEN AND M. S. LOSOWSKY \\ From the University of Leeds Department of Medicine, St. James's Hospital, Leeds
}

SUMMARY A migration inhibition test was used to assess sensitisation of blood leucocytes, and thus cell-mediated immunity, to gluten fraction III in controls and patients with coeliac disease. Migration indices were significantly less (indicating sensitisation) in untreated and in treated patients than in controls, and significantly less in treated patients than in untreated patients. At a concentration of $1 \mathrm{mg} / \mathrm{ml}$ gluten fraction III, $13 \%$ of untreated patients and $54 \%$ of treated patients had migration indices in the sensitised range. At $2 \mathrm{mg} / \mathrm{ml}$ gluten fraction III, sensitisation was demonstrated in $8 \%$ of untreated patients and $48 \%$ of treated patients. After starting a gluten free diet, migration indices fell into the sensitised range in all patients followed. After at least nine months on a gluten free diet, migration indices were significantly higher in those patients with a normal interepithelial lymphocyte count than in those patients with a raised interepithelial lymphocyte count. Cell-mediated immunity to gluten fraction III can be detected in the peripheral blood of certain patients with coeliac disease. Detectable sensitivity is related to the time on a gluten free diet, and the interepithelial lymphocyte count.

The mechanism of gluten toxicity in coeliac disease (CD) is not known, but evidence suggests that cellmediated immunity to gluten may be involved in the production of the intestinal lesion. Mucosal biopsies in untreated coeliac disease show abnormal infiltration of the epithelium with lymphocytes (Ferguson and Murrary, 1971), a local cell-mediated immune reaction in an animal model causes a mucosal lesion with some similarities to that of coeliac disease (MacDonald and Ferguson, 1976) and cultures of the small intestinal mucosa of untreated coeliac disease produce, in the presence of gliadin, a factor which inhibits the migration of normal leucocytes, suggesting that in untreated coeliac disease lymphocytes sensitised to gluten are present in the mucosa (Ferguson et al., 1975).

By measuring transformation of the peripheral blood lymphocytes in the presence of gluten fraction III, Holmes et al. (1976) have shown that some coeliacs have evidence of cell mediated immunity to gluten which is detected more frequently in patients on a gluten free diet than in untreated patients. Sikora et al. (1976) have also shown that a subfraction of gluten fraction III causes transformation of lymphocytes from the peripheral blood of treated patients.

Received for publication 9 August 1977
We have measured cell-mediated immunity to gluten fraction III in adult coeliac disease using the leucocyte migration inhibition test, and related changes in detectable immunity to the duration of treatment with a gluten free diet and to the interepithelial lymphocyte count.

\section{Methods}

\section{SUBJECTS}

Forty-four patients with adult coeliac disease were studied. The diagnosis was made by a mucosal abnormality (subtotal or severe partial villous atrophy) with histological improvement on gluten withdrawal, except in our most recent new cases (three patients) who all had subtotal villous atrophy and a clinical response to gluten withdrawal, but who have not yet been submitted again to biopsy.

Sixteen patients were studied before treatment was started and 38 patients were studied after being on a gluten free diet for at least six months.

Controls comprised 30 healthy volunteers. A second group of controls comprised 13 patients who had undergone small bowel biopsy because of a suspicion of coeliac disease, but in whom the biopsies were normal. The final diagnoses in this group were chronic pancreatitis (two), Crohn's disease (two), nutritional anaemia (two), pernicious anaemia (one), 
anorexia nervosa (one), post-vagotomy malabsorption (three), intestinal lymphangectasia (one), and irritable bowel syndrome (one).

\section{ANTIGEN}

The antigen used was gluten fraction III prepared from BDH gluten according to the method of Frazer et al. (1959). On the basis of preliminary experiments using leucocytes from four controls, two untreated patients, and four treated patients, and gluten fraction III at concentrations of $100 \mu \mathrm{g} / \mathrm{ml}$, $500 \mu \mathrm{g} / \mathrm{ml}, 1 \mathrm{mg} / \mathrm{ml}, 2 \mathrm{mg} / \mathrm{ml}$, and $4 \mathrm{mg} / \mathrm{ml}$, the concentrations of antigen chosen for use in subsequent tests were $1 \mathrm{mg} / \mathrm{ml}$ and $2 \mathrm{mg} / \mathrm{ml}$.

\section{LEUCOCYTE MIGRATION INHIBITION TEST}

Twenty millilitres of peripheral venous blood were defibrinated by shaking with glass beads and mixed with $10 \mathrm{ml}$ dextran 150 in $0.9 \%$ saline under sterile conditions. After sedimentation for 30 minutes the leucocyte-rich supernate was centrifuged for 10 minutes at $1000 \mathrm{rpm}$. The cell pellet was resuspended in $10 \mathrm{ml}$ medium 199 and recentrifuged for a further 10 minutes at $1000 \mathrm{rpm}$. This washing procedure was repeated three times. The cell pellet was resuspended in medium 199 to give a packed cell volume of about $50 \%$. The suspension was drawn into $20-\mu 1$ capillary tubes (Drummond microcaps), which were heat sealed at one end, taking care not to char the cells. The cells were packed by centrifugation at $500 \mathrm{rpm}$ for five minutes. Each capillary tube was cut squarely across just below the cell fluid interface and secured by silicone grease in Sterilin migration chambers which were rimmed with silicone grease. The chambers were filled with appropriate medium, sealed with a coverslip, and incubated at $37^{\circ} \mathrm{C}$ for 20 hours.

Migration chambers were set up in quadruplicate. Control chambers contained medium $199+10 \%$ foetal calf serum, and test chambers contained the same mixture plus $1 \mathrm{mg} / \mathrm{ml}$ or $2 \mathrm{mg} / \mathrm{ml}$ of gluten fraction III.
The image of the migration chambers was projected onto a screen at constant magnification, and the migration areas were traced out and measured by planimetry. (In each case the standard deviation from the mean migration area of each quadruplicate was within $15 \%$ of the mean area.)

The migration index was calculated as mean area of migration in the presence of antigen divided by mean area of migration in the absence of antigen.

Small bowel biopsies were taken from the jejunum using a hydraulically activated capsule (Scott and Losowsky, 1976), within one week after the leucocyte migration inhibition test. When dietary changes were made, biopsy was performed immediately after the blood sample was taken.

\section{Interepithelial lymphocytes}

These were counted 'blind', by the method of Ferguson and Murray (1971). At least 600 epithelial cells were counted, and the results expressed as numbers of lymphocytes per 100 epithelial cells. The upper limit of normal was taken as $\mathbf{4 0}$ lymphocytes per 100 epithelial cells. The Mann-Whitney $U$ test was used in statistical calculations.

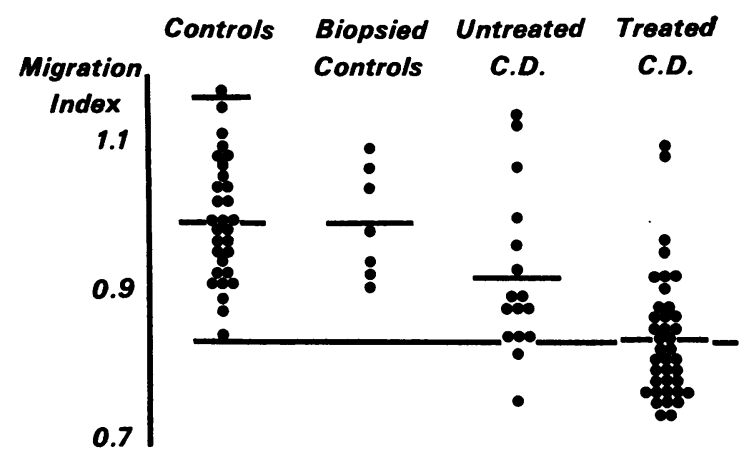

Fig. 1 Migration indices at a concentration of $1 \mathrm{mg} / \mathrm{ml}$ gluten fraction III. Values below $2 S D$ of the mean control value (-) indicate sensitisation to gluten fraction III.

Table 1 Gluten fraction III $1 \mathrm{mg} / \mathrm{ml}$

\begin{tabular}{|c|c|c|c|c|}
\hline \multirow[t]{2}{*}{ Subjects } & \multirow[t]{2}{*}{ Number tested } & \multirow{2}{*}{$\begin{array}{l}\text { Mean migration } \\
\text { index } \pm S D\end{array}$} & \multicolumn{2}{|c|}{ Patients below $2 S D$ of mean control migration index } \\
\hline & & & (no.) & $(\%)$ \\
\hline \multicolumn{5}{|c|}{$\begin{array}{l}\text { Using the Mann-Whitney } U \text { test: } \\
\text { Controls v biopsied controls- } n_{1}=7, n_{2}=30, U=104 \cdot 5, z=0 \cdot 019, P>0.05 \text {. } \\
\text { Controls v untreated } C D-n_{1}=16, n_{2}=30, U=353, z=2 \cdot 606, P<0.01 \\
\text { Controls v treated CD- } n_{1}=30, n_{2}=39, U=102, z=5 \cdot 847, P<0.001 \\
\text { Untreated CD v treated } C D-n_{1}=16, n_{2}=39, U=156.5 ; z=2 \cdot 882, P<0.005 \text {. }\end{array}$} \\
\hline
\end{tabular}


Results

Migration indices for the four groups of subjects at a concentration of $1 \mathrm{mg} / \mathrm{ml}$ gluten fraction III are shown in Fig. 1 and summarised in Table 1. In 30 control subjects there was no inhibition of leucocyte migration by the antigen, as the mean migration index was $1 \cdot 004$.

There was no significant difference between the main group of controls and the biopsied controls. There was a significant inhibition of migration in untreated $(P<0.01)$ and treated coeliac disease $(P<0.001)$ compared with controls, and migration indices were significantly less in treated than in untreated coeliac disease $(\mathrm{P}<0.005)$.

Migration indices in 30 control subjects at each concentration were used to establish the normal range of migration indices with gluten fraction III as antigen. Using probability graph paper, it was shown that migration indices in controls were normally distributed. The $95 \%$ confidence limits (mean \pm 2 SD) were calculated for each control group, and migration indices below 2 SD of the mean control value were taken to indicate sensitisation to gluten fraction III. At $1 \mathrm{mg} / \mathrm{ml}$ gluten fraction III, $13 \%$ of untreated patients and $54 \%$ of treated patients had migration indices in the sensitised range.

Migration indices at a concentration of $2 \mathrm{mg} / \mathrm{ml}$ gluten fraction III are shown in Fig. 2 and summarised in Table 2 . In controls, the mean migration index was $\mathbf{0} \cdot 890$. Thus there was some migration inhibition in controls at this concentration. There was no significant difference between the two groups of controls. Migration indices were significantly lower in untreated $(P<0.01)$ and treated coeliac disease $(P<0.001)$ compared with controls, and migration indices were significantly lower in treated than in untreated coeliac disease $(P<0.02)$.

At a concentration of $2 \mathrm{mg} / \mathrm{ml}$ gluten fraction III, $8 \%$ of untreated patients and $48 \%$ of treated patients had migration indices in the sensitised range.
In order to establish whether detectable sensitisation altered in individual patients after starting a gluten free diet, measurements of migration index before and after starting a gluten free diet were undertaken. Migration indices at a concentration of $1 \mathrm{mg}$ ! ml gluten fraction III are shown during the first year of treatment (Fig. 3). Nine out of 10 patients had migration indices in the normal range before treatment, but in all patients migration indices fell into the sensitised range after starting treatment and thereafter tended to remain constant. In those patients who had serial measurements at a concentration of $2 \mathrm{mg} / \mathrm{ml}$ gluten fraction III (Fig. 4) there was a similar fall in migration index on starting a gluten free diet. After a period of more than one year on a gluten free diet, migration indices in 14 patients tended to remain constant over periods of three months (Fig. 5), thus there were no major fluctuations in detectable sensitivity over short periods when the patient was established on a gluten free diet.

When migration indices in all treated patients were measured at a single point in time (Figs. 1 and 2) about half of the patients had migration indices in the normal range, although migration indices during

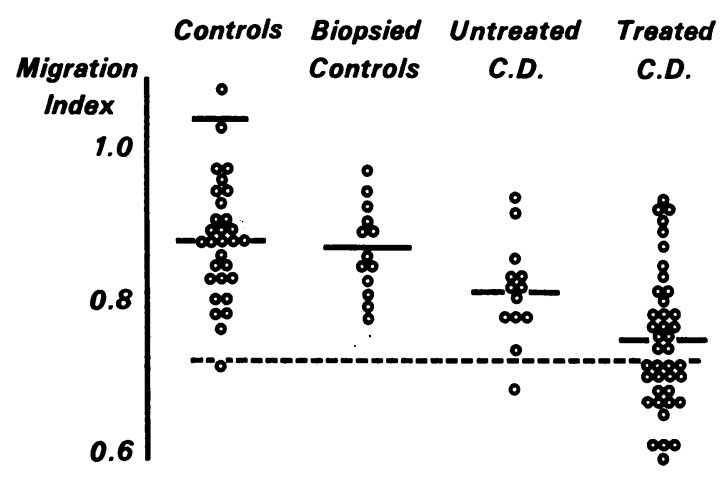

Fig. 2 Migration indices at a concentration of $2 \mathrm{mg} / \mathrm{ml}$ gluten fraction III. Values below $2 S D$ of the mean control value (....) indicate sensitisation to gluten fraction III.

Table 2 Gluten fraction III $2 \mathrm{mg} / \mathrm{ml}$

\begin{tabular}{|c|c|c|c|c|}
\hline \multirow[t]{2}{*}{ Subjects } & \multirow[t]{2}{*}{ Number tested } & \multirow{2}{*}{$\begin{array}{l}\text { Mean migration } \\
\text { index } \pm S D\end{array}$} & \multicolumn{2}{|c|}{ Patients below $2 S D$ of mean control migration index } \\
\hline & & & (no.) & $(\%)$ \\
\hline $\begin{array}{l}\text { Controls } \\
\text { Biopsied controls } \\
\text { Untreated CD } \\
\text { Treated CD }\end{array}$ & $\begin{array}{l}30 \\
13 \\
13 \\
40\end{array}$ & $\begin{array}{l}0.890 \pm 0.079 \\
0.879 \pm 0.059 \\
0.822 \pm 0.066 \\
0.760 \pm 0.091\end{array}$ & $\begin{array}{r}1 \\
19\end{array}$ & $\begin{array}{r}8 \\
48\end{array}$ \\
\hline
\end{tabular}

Using the Mann-Whitney U test :

Controls $v$ biopsied controls- $n_{1}=13, n_{2}=30, U=212, z=0.449, P>0.05$.

Controls v untreated CD- $n_{1}=13, n_{2}=30, U=295, z=2.644, P<0.01$.

Controls $v$ treated $C D-n_{1}=30, n_{2}=40, U=176, z=5.032, P<0.001$.

Untreated CD v treated CD- $n_{1}=13, n_{2}=40, U=146 \cdot 5, z=2 \cdot 346, P<0.02$. 


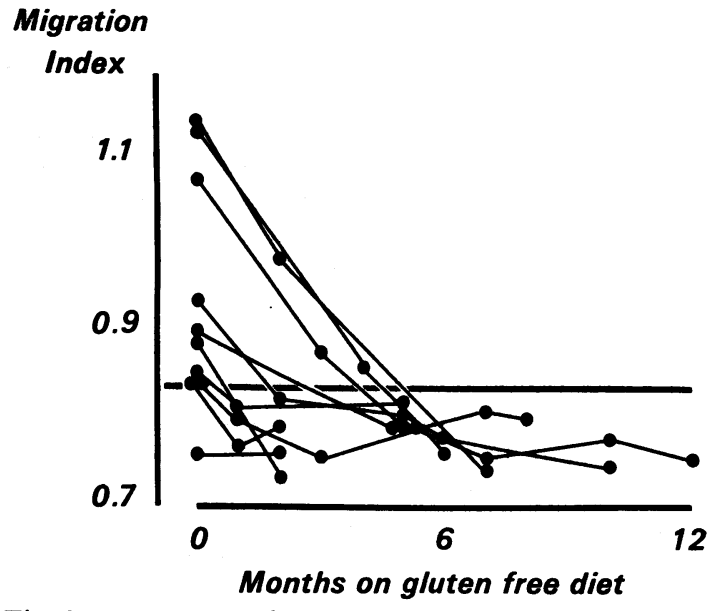

Fig. 3 Migration indices at a concentration of $1 \mathrm{mg} / \mathrm{ml}$ gluten fraction III during the first year on a gluten free diet. $-=$ lower limit of normal.

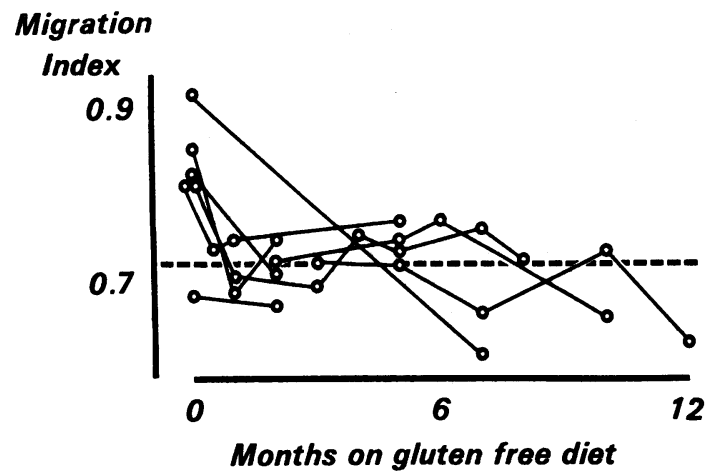

Fig. 4 Migration indices at a concentration of $2 \mathrm{mg} / \mathrm{ml}$ gluten fraction III during the first year on a gluten free diet. .... = lower limit of normal.

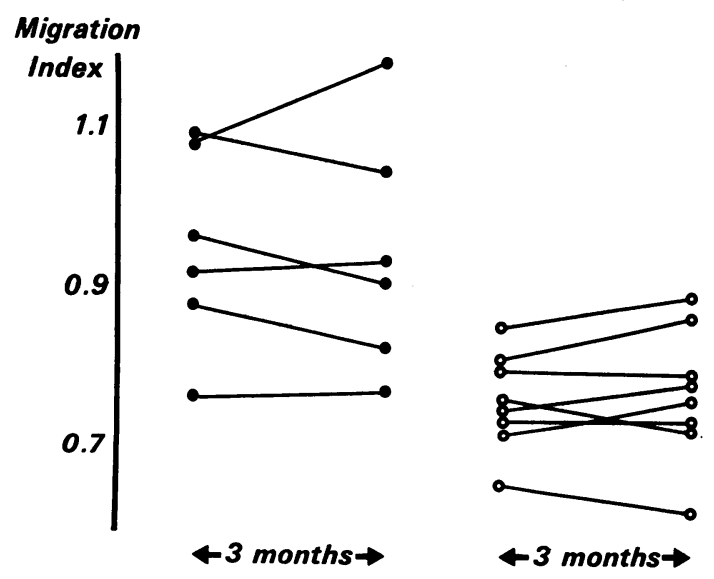

Fig. 5 Migration indices at concentrations of $1 \mathrm{mg} / \mathrm{ml}$ gluten fraction III (O) or $2 \mathrm{mg} / \mathrm{ml}$ gluten fraction III $(O)$ in 14 patients who had been on a gluten free diet for more than one year. the first year of treatment fell into the sensitised range. Presumably detectable sensitivity declines slowly after more than one year on a gluten free diet; we have not followed individual patients for sufficiently long to establish this. Since numbers of interepithelial lymphocytes are known to decline with treatmert, on the hypothesis that interepithelial lymphocytes may be sensitised to gluten and thus a manifestation of the same phenomenon, we have attempted to correlate the sensitivity to gluten in the peripheral blood with the decrease in the interepithelial lymphocyte count.

At each concentration of gluten fraction III (Fig. 6 and Table 3), migration indices were significantly lower $(P<0.002)$ in treated patients with a raised interepithelial lymphocyte count than in treated patients who had achieved a normal interepithelial lymphocyte count-that is, detectable sensitivity in the peripheral blood was lower in those patients who had achieved a normal interepithelial lymphocyte count.

At a concentration of $1 \mathrm{mg} / \mathrm{ml}$ gluten fraction III, only $8 \%$ of treated patients with a normal interepithelial lymphocyte count had migration indices in the sensitised range, whereas $85 \%$ of treated patients with a raised interepithelial lymphocyte count had migration indices in the sensitised range. At $2 \mathrm{mg} / \mathrm{ml}$ gluten fraction III, corresponding percentages were $7 \%$ and $55 \%$.

A patient with coeliac disease who had been on a gluten free diet for six years, and achieved a normal small bowel biopsy with an interepithelial lymphocyte count of 31 lymphocytes/100 epithelial cells was

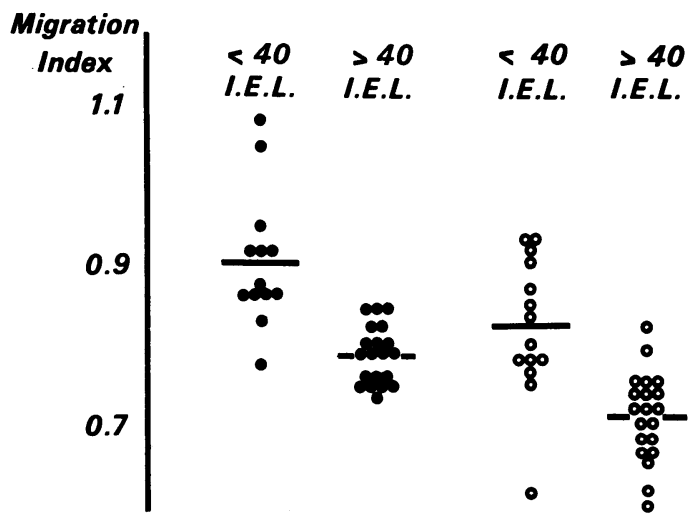

Fig. 6 Migration indices at concentrations of $1 \mathrm{mg} / \mathrm{ml}$ gluten fraction III (O) and $2 \mathrm{mg} / \mathrm{ml}$ gluten fraction III $(\bigcirc)$ in treated patients related to interepithelial lymphocyte count. 


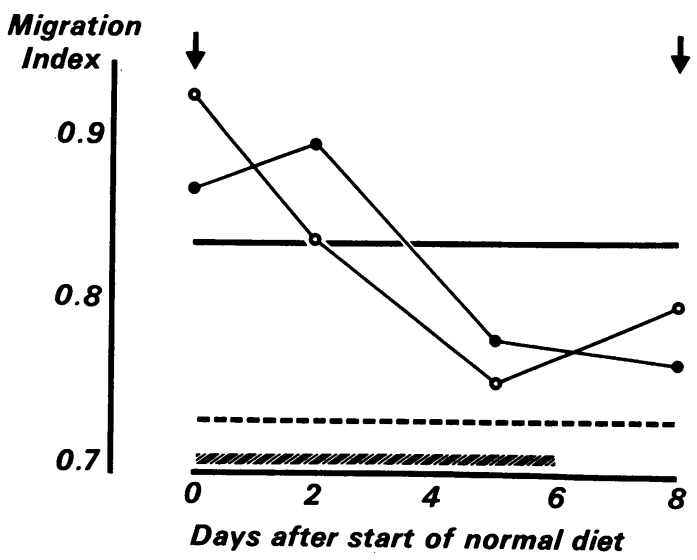

Fig. 7 The effect of gluten challenge for six days on a treated patient. Arrows: jejunal biopsies. $\bigcirc$ : migration indices at $1 \mathrm{mg} / \mathrm{ml}$ gluten fraction III; and $\bigcirc$ : at $2 \mathrm{mg} /$ ml gluten fraction III. - : lower limit of normal for $1 \mathrm{mg} / \mathrm{ml}$ gluten fraction $\mathrm{III} ; . .$. lower limit of normal for $2 \mathrm{mg} / \mathrm{ml}$ gluten fraction $\mathrm{III}$.

given a gluten challenge for six days (Fig. 7). She developed diarrhoea, and a repeat small bowel biopsy after eight days showed definite morphological abnormalities, and an interepithelial lymphocyte count of 88 lymphocytes per 100 epithelial cells. Migration indices at both concentrations of gluten fraction III were initially within the normal range, but by five days fell into the sensitised range at $1 \mathrm{mg} /$ $\mathrm{ml}$ gluten fraction III, and towards the sensitised range at $2 \mathrm{mg} / \mathrm{ml}$ gluten fraction III.

\section{Discussion}

The leucocyte migration inhibition test has been widely used as an in vitro correlate of cell-mediated immunity. The basis of the test is generally thought to be the production of a lymphokine, migration inhibition factor, by sensitised lymphocytes. Although antibodies or immune complexes can affect leucocyte behaviour, it is unlikely that this explains our results, as cells were washed three times and the test was performed using heterologous serum. It therefore seems likely that migration inhibition by gluten fraction III reflects the presence of lymphocytes sensitised to gluten.

On the basis of preliminary experiments we chose to use two concentrations of gluten fraction III in the test, $1 \mathrm{mg} / \mathrm{ml}$ and $2 \mathrm{mg} / \mathrm{ml}$. Holmes et al. (1976) state that concentrations above $4 \mathrm{mg} / \mathrm{ml}$ gluten fraction III are toxic to lymphocytes. We suggest that in our experiments there was some evidence of non-specific toxicity even at $2 \mathrm{mg} / \mathrm{ml}$ gluten fraction III, as in our control subjects at this concentration there was evidence of inhibition of leucocyte migration, without an increase in the number of patients in whom sensitisation was detected.

At a single point in time, $13 \%$ of our untreated patients and $54 \%$ of our treated patients had evidence of sensitisation using $1 \mathrm{mg} / \mathrm{ml}$ gluten fraction III, and at $2 \mathrm{mg} / \mathrm{ml}$ gluten fraction III there was evidence of sensitisation in $8 \%$ of untreated and $48 \%$ of treated patients. These results are comparable with those of Holmes et al., who used lymphocyte transformation to detect cell mediated immunity to $2 \mathrm{mg} / \mathrm{ml}$ and 4 $\mathrm{mg} / \mathrm{ml}$ gluten fraction III. These authors suggested that detectable sensitivity to gluten fraction III in the peripheral blood might depend on the gluten content of the diet, because on a normal diet sensitised lymphocytes may be held in the small bowel, and thus be present in fewer numbers in the peripheral blood. After withdrawal of dietary antigenic stimulation, greater numbers of sensitised lymphocytes might appear in the peripheral blood, accounting for the increased detection of sensitisation in treated compared with untreated patients.

Our results support this suggestion, as, in serial measurements in 10 patients, all nine in whom

Table 3 Using Mann-Whitney $U$ test

\begin{tabular}{|c|c|c|c|c|c|}
\hline & \multirow{2}{*}{$\begin{array}{l}\text { Interepithelial } \\
\text { lymphocyte } \\
\text { count }\end{array}$} & \multirow{2}{*}{$\begin{array}{l}\text { Number of treated } \\
\text { patients tested }\end{array}$} & \multirow{2}{*}{$\begin{array}{l}\text { Mean migration } \\
\text { index } \pm S D\end{array}$} & \multicolumn{2}{|c|}{ Migration indices in sensitised range } \\
\hline & & & & (no.) & $(\%)$ \\
\hline \multicolumn{6}{|c|}{ Gluten fraction III $1 \mathrm{mg} / \mathrm{ml}$} \\
\hline & Below 40 & 13 & $0.916 \pm 0.083$ & 1 & 8 \\
\hline \multirow{3}{*}{ Gluten fraction III $2 \mathrm{mg} / \mathrm{ml}$} & Above 40 & 20 & $0.799 \pm 0.035$ & 17 & 85 \\
\hline & Below 40 & 14 & $0.834 \pm 0.083$ & 1 & 7 \\
\hline & Above 40 & 20 & $0.722 \pm 0.056$ & 11 & 55 \\
\hline
\end{tabular}

At $1 \mathrm{mg} / \mathrm{ml}$ : migration indices in treated patients with raised interepithelial lymphocyte counts $\mathrm{v}$ migration indices in treated patients with normal interepithelial lymphocyte counts,

$n_{1}=13, n_{2}=20, U=15, P<0.002$

At $2 \mathrm{mg} / \mathrm{ml}$ :

$\mathrm{n}_{1}=14, \mathrm{n}_{2}=20, \mathrm{U}=31, \mathrm{P}<0.002$ 
sensitisation was not found before starting treatment showed the development of evidence of sensitisation during the early months on a gluten free diet. We suggest that the reason why sensitisation is not shown in all patients who have been on a gluten free diet for a long period of time is that, after antigenic stimulation with gluten has been withdrawn for a sufficiently long time, the production of sensitised lymphocytes declines. After gluten withdrawal, the distribution of sensitised lymphocytes is no longer influenced by the presence of antigen and the number of sensitised cells in the peripheral blood may then be reflected by the interepithelial lymphocyte count. This would explain why detection of sensitivity in peripheral blood correlates with the interepithelial lymphocyte count in treated patients, and why gluten is not toxic to the mucosa from a patient with treated CD when cultured in vitro (Jos et al., 1974), there being insufficient sensitised lymphocytes to produce the effects of a cell-mediated immune response.

It seems that gluten fraction III is unlikely to be useful as the antigen in a screening test detecting cell mediated immunity in all patients with $C D$, untreated and well treated. This may be because the part of gluten fraction III to which sensitisation is detected is in relatively low concentration, and a sufficiently high concentration of antigen to show sensitisation in those with few sensitised lymphocytes would be toxic to the cells. It is possible that a more sensitive test-for example, by using a purified antigenwould show evidence of cell-mediated immunity to gluten in all patients with coeliac disease, including those who had few circulating sensitised lymphocytes. The purified fraction of gluten used by Sikora et al. in lymphocyte transformation studies shows promise, although results in untreated patients are not yet published.

In a treated patient who had no detectable sensitivity to gluten fraction III in the peripheral blood, a gluten challenge restored detectable sensitivity after five days. The timing of this response suggests the stimulation of immunological memory, with sudden increase in the production of sensitised cells. We speculate that, if antigenic stimulation had been continued, detectable sensitivity may have again declined because of sequestration of sensitised lym- phocytes in the mucosa. It was felt, however, that the challenge had confirmed the diagnosis and that it would have been unjustifiable to continue gluten in the diet of this patient.

Studies of cell-mediated immunity to gluten in normal subjects shortly after starting a gluten free diet should be undertaken in order to be sure that the effect that we have demonstrated is confined to those with coeliac disease; furthermore, studies of changes in cell-mediated immunity to other food antigens after starting a gluten free diet in controls and in patients with coeliac disease are necessary to demonstrate the specificity of the response. However, our results support the suggestion that cell-mediated immunity to gluten may be involved, primarily or secondarily, in the pathogenesis of the mucosal lesion of coeliac disease.

\section{References}

Ferguson, A., MacDonald, T. T., McClure, J. P., and Holden, R. J. (1975). Cell-mediated immunity to gliadin within the small-intestinal mucosa in coeliac disease. Lancet, 1, 895-897.

Ferguson, A., and Murray, D. (1971). Quantitation of intraepithelial lymphocytes in human jejunum. Gut, 12, 988994.

Frazer, A. C., Fletcher, R. F., Ross, C. A. C., Shaw, B., Sammons, H. G., and Schneider, R. (1959). Gluteninduced enteropathy. The effect of partially digested gluten. Lancet, 2, 252-255.

Holmes, G. K. T., Asquith, P., and Cooke, W. T. (1976). Cellmediated immunity to gluten fraction III in adult coeliac disease. Clinical and Experimental Immunology, 24, 259 265.

Jos, J., Lenoir, G., De Rites, G., and Ray, J. (1974). In vitro culturing of biopsies from children. In Coeliac Disease: Proceedings of the Second International Coeliac Symposium, pp. 91-105. Edited by W. T. J. M. Hekkens and A. S. Peña. Stenfert Kroese: Leyden.

MacDonald, T. T., and Ferguson, A. (1976). Hypersensitivity reactions in the small intestine. 2. Effects of allograft rejection on mucosal architecture and lymphoid cell infiltrate. Gut, 17, 81-91.

Scott, B. B., and Losowsky, M. S. (1976). Peroral smallintestinal biopsy: experience with the hydraulic multiple biopsy instrument in routine clinical practice. Gut, 17, 740743.

Sikora, K., Anand, B. S., Truelove, S. C., Ciclitira, P. J., and Offord, R. E. (1976). Stimulation of lymphocytes from patients with coeliac disease by a subfraction of gluten. Lancet, 2, 389-391. 